\title{
Genetic association between sexual maturity and weekly live-weights in laying-type Japanese quail
}

\author{
M. Sezer ${ }^{\#}$, E. Berberoglu and Z. Ulutas \\ Gaziosmanpasa University, Faculty of Agriculture, Department of Animal Science, Tokat 60240, Turkey
}

\begin{abstract}
This study focused on the estimation of genetic relationships between weekly live weights and sexual maturity of male and female Japanese quail. The live body weight data of a laying-type quail line over time were collected from hatching to six weeks of age. Sexual maturity was determined as the day of production of cloacal gland foam for males, and the day of laying the first egg for females. (Co)Variance components and genetic parameters were estimated, using MTDFREML, a restricted maximum likelihood (REML) procedure using a model with direct and maternal genetic effects. Heritability estimates of weekly live weights ranged from moderate to high $(0.20-0.60)$, and were higher for males than for females. The variance due to maternal effects disappeared gradually for males but rapidly for females as the chicks grew older. Heritability of age of sexual maturation was $0.24 \pm 0.008$ and $033 \pm 0.136$ for males and females, respectively. Genetic correlations between ages of reaching sexual maturity and live weights (except hatchling weight) were favourable for males $(-0.16$ to -0.45$)$ and unfavourable for females $(0.14$ to 0.22$)$. Genetic correlations between males and females ranged from moderate $(0.46 \pm 0.083)$ to high $(0.98 \pm 0.139)$ for weekly live weights, and were $0.71 \pm 0.24$ for age of reaching sexual maturity. Sexual size dimorphism can be explained by the differences in pattern of heritability and correlation estimates between reaching sexual maturity and live weights for males and females.
\end{abstract}

Keywords: Quail, Coturnix coturnix japonica, genetic relationships, sexual dimorphism

${ }^{\#}$ Corresponding author. E-mail: msezer@gop.edu.tr

\section{Introduction}

During recent years efforts have been made to increase the live weight of the Japanese quail (Coturnix coturnix japonica). Knowledge of the heritability of traits is essential for understanding how individual characteristics change from one generation to another in response to selection (Falconer \& Mackay, 1996). Studies of heritability have mostly focused on the estimation of genetic parameters for growth especially under different selection environments (Anthony et al., 1996; Marks, 1996; Saatci et al., 2003). However, selection rarely operates on only one characteristic at a time (Lande \& Arnold, 1983). Hence, if there is a genetic correlation between characteristics under selection, the overall response to selection will change according to the heritability of the traits examined, and strength and sign of the genetic covariance among them (Jensen et al., 2003).

The Japanese quail is a sexually dimorphic bird with females having a larger body size than males, unlike other poultry species. Accordingly, females require more time to reach sexual maturity than males (Reddish et al., 2003). The differences in growth pattern between the sexes are also a well-known phenomenon (Balcioglu et al., 2005; Sezer \& Tarhan, 2005). Sexual dimorphism is believed to evolve under the pressure of natural and sexual selection, which implies that genes controlling sexually dimorphic characteristics differ between males and females (Mignon-Grasteau et al., 2004). Therefore, it has been suggested that genetic parameters for male and female Japanese quails should be estimated separately (Sefion \& Siegel, 1974), otherwise, it would be assumed that genetic correlations between male and female traits are equal to one and variances of both traits are equal, which is not often the case.

In the literature several reports on estimates of genetic parameters for live weight of Japanese quail are available based on the restricted maximum likelihood method. Additive genetic effect of individuals can be estimated precisely with the animal model, incorporating several fixed effects such as hatchling group and sex (Aggrey \& Cheng, 1994; Saatci et al., 2003). On the other hand, it is important to have a wider knowledge of genetic correlations between live weight and other important traits for quail production to develop an optimal total merit index. This will also complement our understanding of the evolutionary 
consequences of the sexual dimorphism. Therefore, the objectives of the current study were to estimate genetic parameters of weekly live weights and age of sexual maturity and correlations between them for male and female Japanese quails.

\section{Material and Methods}

The data for this study were obtained from the Japanese quail population at the Quail Breeding Unit of Gaziosmanpasa University, Tokat, Turkey. Adult female birds were housed in individual stainless steel wire mesh cages for accurate pedigree identification. Each male was mated with two females over two generation. Mating was controlled by allowing a male to stay with an allocated female for one day. Parents of the second generation were chosen from the first batch of birds, and mated when they were 75 days old. Special care was taken to avoid inbreeding among parental birds used for mating.

Egg collection started one week after the beginning of mating to ensure that all eggs were fertile. Eggs were collected daily until a maximum of 10 eggs were obtained per female. For accurate pedigree identification sire and dam numbers were recorded for each egg. When the chicks hatched after artificial incubation, they were labelled with wing-rings and placed randomly in quail battery brooders. Birds were housed for the first three weeks under 24 hours lighting, and for the following weeks in a 16:8 light : dark cycle. Indoor air temperature for the newly hatched chicks was $36{ }^{\circ} \mathrm{C}$. Temperature was decreased by $3{ }^{\circ} \mathrm{C}$ every consecutive week until it reached $24^{\circ} \mathrm{C}$. Birds were allowed ad libitum access to food and water. They were fed a starter diet containing $240 \mathrm{~g}$ crude protein (CP)/kg and $13.39 \mathrm{MJ}$ metabolisable energy (ME)/kg for 21 days, a grower diet containing $190 \mathrm{~g} \mathrm{CP} / \mathrm{kg}$ and $12.55 \mathrm{MJ} \mathrm{ME} / \mathrm{kg}$ between 22 and 35 days of age and thereafter a breeder diet containing $170 \mathrm{~g} \mathrm{CP} / \mathrm{kg}$ and $11.50 \mathrm{MJ} \mathrm{ME} / \mathrm{kg}$.

Birds were weighed weekly from hatching (HW) to six weeks of age (W6) on an electronic balance with a sensitivity of $0.01 \mathrm{~g}$. Japanese quail males are unique among birds in having a well developed proctodeal gland. The foam produced by this gland is an androgen dependent secondary sex characteristic in Japanese quail and an external indicator of sexual maturity in the male. Females and castrated males do not produce foam (Siewert \& Adkins-Regan, 1998; Adkins-Regan, 1999; Mohan et al., 2002). Therefore, from 25 days of age males were inspected daily to determine the onset of cloacal gland foam production. This day was recorded as the age of reaching sexual maturity (ASM) of a male. After the last weighing, females were transferred to individual cages to determine age of reaching sexual maturity. Since female quails do not need to be stimulated to start producing eggs, the day of laying the first egg was recorded as the ASM for a female (Reddish et al., 2003).

The sex of the Japanese quails was determined correctly by the plumage coloration at 21 days of age. Therefore, records from quails that died before 21 days of age were removed from the data set. Analyses were carried out with records of 1909 quails (998 males and 911 females), the progeny of 193 sires and 309 dams in 14 hatchling groups (generation). Variance components, direct-maternal genetic covariance and genetic parameters were estimated using REML procedures (MTDFREML software; Boldman et al., 1995). For each trait, hatchling group was included as a fixed effect in the animal model. An animal was fitted at random in the model to estimate direct additive genetic variance. Maternal additive genetic effect was taken into account by including the dam as second random effect. The statistical significance of random effects was determined for each trait using likelihood ratio tests (Morrell, 1998). A new value was calculated by multiplying the difference in log-likelihood scores by negative 2 . Then, models were compared by considering if the calculated value was higher than the $\chi^{2}$ value with 1 degree of freedom for each additional (co)variance component in the more complex model:

$$
\mathrm{Y}_{\mathrm{ijk}}=\mu+\mathrm{a}_{\mathrm{i}}+\mathrm{m}_{\mathrm{j}}+\mathrm{b}_{\mathrm{k}}+\mathrm{e}_{\mathrm{ijk}}
$$

where $\mu$ is the population mean, $a_{i}$ is the additive animal genetic effect $m_{j}$ is the additive maternal genetic effect, $b_{k}$ is the effect of hatchling group, $\mathrm{e}_{\mathrm{ijk}}$ is the residual error.

Genetic and phenotypic correlations between traits and across sexes were estimated in two trait analyses with the same fix and random effects as above. Genetic correlations across sexes were estimated separately for each trait in the models. Two new variables were constructed for each trait, one for male and another for the female trait value. If the individual was a male the female trait value was missing, and vice versa. 
The degree of differences between male and female (DSD) in live weight and ASM was calculated by the following formula:

Degree of sexual dimorphism $(\mathrm{DSD})=\left[\frac{\mathrm{FW}_{\mathrm{t}}-\mathrm{MW}_{\mathrm{t}}}{\mathrm{FW}_{\mathrm{t}}}\right] \times 100$

where: $\mathrm{FW}_{\mathrm{t}}$ is the mean female live weight at time $\mathrm{t}$ and $\mathrm{MW}_{\mathrm{t}}$ is the mean male live weight at time $\mathrm{t}$.

\section{Results and Discussion}

Since the study was carried out with 14 hatchings, descriptive statistics of live weight and ASM were tabulated only within gender groups, and presented in Table 1. Weekly live weights (except hatchling weight) of the males and females were different from each other $(\mathrm{P}<0.01)$. Live weights of Japanese quail from hatching to six week of age were similar to those reported in the literature (for review, see Saatci et al., 2003).

Table 1 Descriptive statistics for weekly live weight (g) and age of sexual maturation (ASM) (d) for males and females along with the degree of sexual dimorphism (DSD, \%)

\begin{tabular}{ccrccccc}
\hline & \multicolumn{1}{c}{ Male } & \multicolumn{5}{c}{ Female } & \multirow{2}{*}{ DSD } \\
\cline { 2 - 6 } HW & 998 & $8.22 \pm 0.02$ & 10 & 911 & $8.25 \pm 0.03$ & 10 & 0.36 \\
W1 & 993 & $23.70 \pm 0.15$ & 20 & 908 & $24.57 \pm 0.16$ & 20 & 3.54 \\
W2 & 995 & $54.68 \pm 0.30$ & 17 & 910 & $56.40 \pm 0.32$ & 17 & 3.05 \\
W3 & 997 & $96.20 \pm 0.43$ & 14 & 910 & $99.40 \pm 0.48$ & 15 & 3.22 \\
W4 & 995 & $132.96 \pm 0.51$ & 12 & 906 & $138.13 \pm 0.60$ & 13 & 3.74 \\
W5 & 978 & $163.30 \pm 0.50$ & 9 & 882 & $177.51 \pm 0.69$ & 12 & 8.01 \\
W6 & 913 & $181.79 \pm 0.56$ & 9 & 824 & $204.76 \pm 0.75$ & 11 & 11.22 \\
ASM & 639 & $32.96 \pm 0.18$ & 13 & 647 & $45.82 \pm 0.22$ & 12 & 28.01 \\
\hline
\end{tabular}

$\mathrm{N}$ - number of observation; s.e. - standard error of mean; CV - coefficient of variation $\mathrm{HW}$ - hatchling weight; W1 to W6 - weight at one to six weeks of age

In many species, members of the larger sex begin to produce gametes at an older age than members of the smaller sex. This could be expected, because members of the larger sex require more time to grow to a larger size (Anderson, 1994; Charlesworth, 1994), or they postpone the development of fully adult characteristics until they have acquired the experience necessary to breed successfully (Stearns, 1992). On the other hand, in many bird species showing sexual dimorphism, both sexes begin to produce gametes at the same age, but members of the larger sex delay final reproductive development to an older age (Stamps \& Krishnana, 1997). In this study there were no differences in hatchling weight between males and females. Degree of sexual dimorphism (DSD) was low between W1 and W4 (between 3.05 and 3.74\%), but increased notably at later weighings (Table 1), in agreement with results presented by Hort et al. (1999). On the other hand, time required for sexual maturation of females $(45.82 \pm 0.22)$ was $28.01 \%$ longer than that of males $(32.96 \pm 0.18)$. These values of ASM were within the range reported by Reddish et al. (2003). This pattern of sexual bi-maturation could be advantageous for both males and females. While males would have a chance to find a mate or territory early, females would have time to develop fully for future production of viable gametes.

Estimated direct and maternal heritability of the weekly live weights, ASM and genetic correlation between male and female are presented in Table 2. The highest maternal heritability was estimated for hatchling weights (HW). Maternal effects would bias the heritability estimate upwards by means of the weight at hatching and tend to be stronger earlier rather than later. The variance due to maternal additive 
effects disappeared after W2 in females, but decreased gradually for males. Direct heritability of live weight was the lowest at W2, and increased steadily afterwards. Ricklefs (1985) expressed the importance of the early growth on later body weight, as growth rate is more flexible. In this study, the genetic variances partitioned into direct and maternal components. Therefore, the decrease might be the result of high variation at W1 and W2 due to a lag phase in the Japanese quail's growth curve. Generally, the direct heritability estimates of live weights for males were higher than those of females. The heritability estimates in this study were similar to those reported by Michalska (1994), Marks (1996) and Schüler et al. (1998), but were higher than those reported by Aggrey \& Cheng (1994) and Saatci et al. (2003). The heritability of the ASM was moderate and similar for males and females.

Table 2 Estimates of direct $\left(\mathrm{h}^{2}\right)$ and maternal $\left(\mathrm{m}^{2}\right)$ heritability, and direct-maternal genetic correlation $\left(\mathrm{r}_{\mathrm{am}}\right)$ for weekly live weights and age of sexual maturity and across sexes genetic correlations for the same trait

\begin{tabular}{|c|c|c|c|c|c|c|c|}
\hline \multirow{2}{*}{$\begin{array}{l}\text { Time } \\
\text { pints }\end{array}$} & \multicolumn{3}{|c|}{ Male } & \multirow{2}{*}{$\begin{array}{c}\text { Genetic } \\
\text { correlations }\end{array}$} & \multicolumn{3}{|c|}{ Female } \\
\hline & $h^{2}$ & $\mathrm{~m}^{2}$ & $r_{a m}$ & & $h^{2}$ & $\mathrm{~m}^{2}$ & $\mathrm{r}_{\mathrm{am}}$ \\
\hline HW & $0.24 \pm 0.094$ & $0.58 \pm 0.106$ & $-0.29 \pm 0.25$ & $0.82 \pm 0.120$ & $0.20 \pm 0.102$ & $0.55 \pm 0.070$ & $-0.22 \pm 0.18$ \\
\hline W1 & $0.46 \pm 0.101$ & $0.33 \pm 0.099$ & $-0.85 \pm 0.12$ & $0.98 \pm 0.139$ & $0.31 \pm 0.103$ & $0.29 \pm 0.079$ & $-0.62 \pm 0.16$ \\
\hline W2 & $0.33 \pm 0.100$ & $0.14 \pm 0.084$ & $-0.70 \pm 0.21$ & $0.91 \pm 0.195$ & $0.13 \pm 0.075$ & $0.08 \pm 0.061$ & N.S. \\
\hline W3 & $0.44 \pm 0.110$ & $0.15 \pm 0.087$ & $-0.71 \pm 0.18$ & $0.56 \pm 0.108$ & $0.20 \pm 0.096$ & $0.01 \pm 0.051$ & N.S. \\
\hline W4 & $0.47 \pm 0.113$ & $0.20 \pm 0.094$ & $-0.60 \pm 0.20$ & $0.46 \pm 0.083$ & $0.35 \pm 0.094$ & $0.05 \pm 0.046$ & N.S. \\
\hline W5 & $0.57 \pm 0.113$ & $0.06 \pm 0.075$ & N.S. & $0.54 \pm 0.086$ & $0.34 \pm 0.107$ & $0.01 \pm 0.053$ & N.S. \\
\hline W6 & $0.60 \pm 0.120$ & $0.07 \pm 0.082$ & N.S. & $0.55 \pm 0.094$ & $0.41 \pm 0.115$ & $0.02 \pm 0.059$ & N.S. \\
\hline ASM & $0.24 \pm 0.118$ & $0.09 \pm 0.114$ & N.S. & $0.71 \pm 0.240$ & $0.33 \pm 0.136$ & $0.01 \pm 0.071$ & N.S. \\
\hline
\end{tabular}

N.S. - not significant; HW - hatchling weight; W1 - W6 - weight at one to six weeks of age ASM - age of sexual maturity

The genetic correlations of live weight across sexes ranged from moderate $(0.46 \pm 0.083)$ to high 0.98 \pm 0.139 ), and it was estimated as $0.71 \pm 0.240$ for ASM (Table 2). Genes that are identical in both sexes are expected to produce a strong positive across sex genetic correlation. Intersexual genetic correlation was estimated to be lower than one, and this was most pronounces after two weeks of age. Additionally, the high heritability estimate of live weight in males indicates that additive genetic variance in the two sexes is different from one another. One of the explanations for different levels of additive genetic variance between two sexes, is sex-linked genes. Because the female is the heterogametic sex in quails, males are expected to have a higher level of additive genetic variance than females when genes are sex-linked (Lynch \& Walsh, 1998). This could also be a result of genes in the genome expressed in both sexes through the effects of sexually antagonistic alleles (Chippindale et al., 2001) leading to sexual dimorphism. Sexual differences in sensitivity to environmental conditions during the period of growth may also result in a different heritability between males and females (Potti \& Merino, 1996).

Estimated genetic and phenotypic correlations of weekly live weights and ASM are presented in Table 3 for males and in Table 4 for females. The genetic and phenotypic correlations between live weights decreased as the time intervals between them increased. Among the successive live weights, the lowest genetic ( 0.29 and 0.31$)$ and phenotypic $(0.34$ and 0.38$)$ correlations were detected between HW and W1 for males and females, respectively. Genetic correlations between W2 and W6 were estimated as 0.76 and 0.73 by Brah et al. (1997) and Saatci et al. (2003), respectively. The genetic correlation between W2 and W6 estimated in this study was higher for females $(0.81 \pm 0.15)$, but lower for males $(0.57 \pm 0.11)$ than reported genetic correlations. These high genetic correlations between live weights at younger and older ages support the general view of the possibility of selecting Japanese quails based on early body weight (Aggrey \& Cheng, 1994). 
Genetic and phenotypic correlations between ASM and weekly live weight of males were favourable and high in magnitude. It seems that males with genetically high growth potential are most likely to reach sexual maturity faster than the ones with low growth potential. Although early maturity is expected to cause inhibition of growth, reduction in quality or survival of offspring (Oli et al., 2002), such a trade-off between early sexual maturity and live weight should be stabilized evolutionarily, because of the importance of growth trajectories in the live weight history of species. These will also provide obvious benefits for, especially wild male quails because of the advantage of finding a mate or a territory at an early age. On the other hand, males start to produce mating calls of high frequency when they are sexually mature. These mating calls may attract predators to the nesting site. Hence, early maturity of males could be important to allow the necessary time for females to develop safely without the risk of predator attacks.

Table 3 Genetic and phenotypic parameters for male Japanese quails. Genetic correlations above and phenotypic correlations below the diagonal with their standard errors

\begin{tabular}{ccccccccc}
\hline $\begin{array}{c}\text { Time } \\
\text { point }\end{array}$ & HW & W1 & W2 & W3 & W4 & W5 & W6 & ASM \\
\hline HW & & $0.29 \pm 0.19$ & $-0.10 \pm 0.25$ & $-0.10 \pm 0.24$ & $-0.17 \pm 0.25$ & $0.02 \pm 0.20$ & $0.07 \pm 0.05$ & $0.34 \pm 0.26$ \\
W1 & $0.34 \pm 0.04$ & & $0.86 \pm 0.06$ & $0.73 \pm 0.10$ & $0.64 \pm 0.12$ & $0.55 \pm 0.13$ & $0.48 \pm 0.13$ & $-0.31 \pm 0.25$ \\
W2 & $0.28 \pm 0.04$ & $0.80 \pm 0.01$ & & $0.94 \pm 0.03$ & $0.85 \pm 0.05$ & $0.72 \pm 0.08$ & $0.57 \pm 0.11$ & $-0.40 \pm 0.24$ \\
W3 & $0.26 \pm 0.04$ & $0.68 \pm 0.02$ & $0.85 \pm 0.01$ & & $0.91 \pm 0.03$ & $0.76 \pm 0.05$ & $0.63 \pm 0.07$ & $-0.45 \pm 0.21$ \\
W4 & $0.29 \pm 0.04$ & $0.58 \pm 0.03$ & $0.77 \pm 0.01$ & $0.86 \pm 0.01$ & & $0.87 \pm 0.04$ & $0.75 \pm 0.06$ & $-0.38 \pm 0.22$ \\
W5 & $0.29 \pm 0.04$ & $0.47 \pm 0.03$ & $0.57 \pm 0.02$ & $0.67 \pm 0.02$ & $0.74 \pm 0.01$ & & $0.94 \pm 0.03$ & $-0.22 \pm 0.22$ \\
W6 & $0.27 \pm 0.04$ & $0.34 \pm 0.04$ & $0.44 \pm 0.03$ & $0.51 \pm 0.02$ & $0.58 \pm 0.02$ & $0.81 \pm 0.01$ & & $-0.16 \pm 0.22$ \\
ASM & $-0.05 \pm 0.05$ & $-0.32 \pm 0.04$ & $-0.41 \pm 0.04$ & $-0.44 \pm 0.03$ & $-0.41 \pm 0.04$ & $-0.28 \pm 0.05$ & $-0.14 \pm 0.05$ & \\
\hline
\end{tabular}

HW - hatchling weight; W1 to W6 - weight at one to six weeks of age

ASM - age of sexual maturity

Table 4 Genotypic and phenotypic parameters for male Japanese quails. Genetic correlations above and phenotypic correlations below the diagonal with their standard errors

\begin{tabular}{ccccccccc}
\hline $\begin{array}{c}\text { Time } \\
\text { point }\end{array}$ & HW & W1 & W2 & W3 & W4 & W5 & W6 & ASM \\
\hline HW & & $0.31 \pm 0.12$ & $0.46 \pm 0.16$ & $0.46 \pm 0.15$ & $0.20 \pm 0.13$ & $0.36 \pm 0.13$ & $0.24 \pm 0.13$ & $-0.15 \pm 0.16$ \\
W1 & $0.38 \pm 0.04$ & & $0.49 \pm 0.13$ & $0.35 \pm 0.12$ & $0.30 \pm 0.12$ & $0.41 \pm 0.11$ & $0.32 \pm 0.12$ & $0.16 \pm 0.27$ \\
W2 & $0.31 \pm 0.04$ & $0.77 \pm 0.02$ & & $0.95 \pm 0.05$ & $0.89 \pm 0.10$ & $0.94 \pm 0.11$ & $0.81 \pm 0.15$ & $0.15 \pm 0.26$ \\
W3 & $0.32 \pm 0.04$ & $0.57 \pm 0.03$ & $0.88 \pm 0.01$ & & $0.98 \pm 0.03$ & $0.87 \pm 0.02$ & $0.82 \pm 0.02$ & $0.14 \pm 0.24$ \\
W4 & $0.26 \pm 0.04$ & $0.54 \pm 0.03$ & $0.77 \pm 0.02$ & $0.86 \pm 0.01$ & & $0.94 \pm 0.03$ & $0.84 \pm 0.04$ & $0.14 \pm 0.22$ \\
W5 & $0.25 \pm 0.04$ & $0.43 \pm 0.04$ & $0.67 \pm 0.02$ & $0.72 \pm 0.01$ & $0.85 \pm 0.01$ & & $0.89 \pm 0.03$ & $0.22 \pm 0.21$ \\
W6 & $0.29 \pm 0.05$ & $0.36 \pm 0.04$ & $0.55 \pm 0.02$ & $0.67 \pm 0.01$ & $0.76 \pm 0.03$ & $0.80 \pm 0.02$ & & $0.18 \pm 0.21$ \\
ASM & $-0.15 \pm 0.05$ & $-0.22 \pm 0.05$ & $-0.24 \pm 0.04$ & $-0.23 \pm 0.05$ & $-0.21 \pm 0.05$ & $-0.27 \pm 0.05$ & $-0.24 \pm 0.05$ & \\
\hline
\end{tabular}

HW - hatchling weight; W1 to W6 - weight at one to six weeks of age

ASM - age of sexual maturity

Phenotypic correlations between ASM and weekly live weight of females were also negative. Genetic correlations estimated between live weights and ASM for females were low and unfavourable, but they were 
generally not different from zero. Delayed maturity of the females, on the other hand, allows additional growth or experience and ability to produce larger offspring (Oli et al., 2002), leading to increased future reproductive output of the female. Reports of correlation between age of sexual maturity and live weight varied from moderately positive to moderately negative (Liu et al., 1995). Reaching sexual maturity is influenced by chronological age, body weight and body composition (Siegel \& Dunnigton, 1985). On the other hand, the interaction between them for the onset of sexual maturity is inseparable (Oruwari \& Brody, 1988, Reddish et al., 2003). Kerr et al., (2001) reported the effect of exponential growth rate and indications of critical period of development on age at first egg (between 14 and 42 days of age) in meat-type chickens. Akbas \& Oguz (1998) reported that Japanese quails with lighter final weights reached final weight at younger ages than heavier birds. Consequently, genetic correlation between the parameter K, which describes earliness of maturing, and the weight at sexual maturation varied from low to moderate $(0.09$ to 0.26 , depending on the growth model). Hence it could be possible to see the same pattern reported here if the correlations would be estimated for males and females. The other explanation includes multiple thresholds concept in which body weight and selected aspect of body composition must exceed a threshold value in order for sexual development to proceed (Reddish et al., 2003). The other reason for such a low correlation between live weight and ASM could be that the time period required for laying the first egg gets longer for females that are not only under but also above the optimum weight.

\section{Conclusions}

There is indication that genes controlling sexually dimorphic characteristics differ between male and female Japanese quails. Therefore, it could not be assumed that the genetic correlation between male and female traits should be equal to one and that variances of both traits are equal. It is important to be aware of the genetic correlation between live weight and age of sexual maturation in commercial quail production, to develop an optimal total merit index. The genetic correlation between live weight and age of sexual maturation was unfavourable for females but not very strong, indicating availability of birds with suitable breeding values for high weight and early maturity.

\section{Acknowledgements}

This study was supported by the Scientific Research Project Committee of GOP University, Tokat, Turkey, Grant No. 2001/41.

\section{References}

Adkins-Regan, E., 1999. Foam produced by male Coturnix quail: What is its function? Auk 116, 184-193.

Aggrey, S.A. \& Cheng, K.M., 1994. Animal model analysis of genetic (co)variances for growth traits in Japanese quail. Poult. Sci. 73, 1822-1828.

Akbas, Y. \& Oguz, I., 1998. Growth curve parameters of lines of Japanese quail (Coturnix coturnix japonica), unselected and selected for four-week body weight. Arch Geflügelk 62, 104-109.

Anderson, M., 1994. Sexual Selection. Princeton University Press, Princeton, New Jersey, USA.

Anthony, N.B., Nestor, K.E. \& Marks, H.L., 1996. Short-term selection for four-week body weight in Japanese quail. Poult. Sci. 75, 1192-1197.

Balcıoglu, M.S., Kızılkaya, K., Yolcu, H.İ. \& Karabağ, K., 2005. Analysis of growth characteristics in shortterm divergently selected Japanese quail. S. Afr. J. Anim. Sci. 35, 83-89.

Boldman, K.G., Kriese, L.A., Van Vleck, L.D. \& Kachman, S.D., 1995. A manual for use of MTDFREML. USDA-ARS, Clay Center, Nebraska, USA.

Brah, G.S., Chaudhary, M.L. \& Sandhu, J.S., 1997. Genetic analyses of body weight in three lines of Japanese quail. Ind. J. Poult. Sci. 32, 242-248.

Charlesworth, B., 1994. Evolution in Age-Structured Populations (2nd ed.). Cambridge University Press, Cambridge, UK.

Chippindale, A.K., Gibson, J.R. \& Rice, W.R., 2001. Negative genetic correlation for adult fitness between sexes reveals ontogenetic conflict in Drosophila. Proc. Nat. Acad. Sci., USA. 98, 1671-1675.

Falconer, D.S. \& Mackay, T.F.C., 1996. Introduction to Quantitative Genetics (4th ed.). Longman, London.

Hort, J., Hyankova, L. \& Knizetova, H., 1999. The role of sexual dimorphism in the onset of egg-laying in Japanese quail. Proc. Poult. Gen. Symp. 6 - 8 October 1999, Mariencee/Germany. pp. 120. 
Jensen, H., Saether, B.E., Ringsby, T.H., Tufto, J., Griffith, S.C. \& Ellegren, H., 2003. Sexual variation in heritability and genetic correlations of morphological traits in house sparrow (Passer domesticus). J. Evol. Biol. 16, 1296-1307.

Kerr, C.L., Hammerstedt, R.H. Barbato, G.F., 2001. Effects of selection for exponential growth rate at different ages on reproduction in chickens. Avian Poult. Bio. Rev. 12, 127-136.

Liu, G., Dunnington, E.A. \& Diegel, P.B., 1995. Correlated responses to long-term divergent selection for eight-week body weight in chickens: growth, sexual maturity, and egg production. Poult. Sci. 74, $1259-1268$.

Lynch, M. \& Walsh, B., 1998. Genetics and Analysis of Quantitative Traits. Sinauer Associates, Inc., Sunderland, USA.

Marks, H.L., 1996. Long-term selection for body weight in Japanese quail under different environments. Poult. Sci. 75, 1198-1203.

Michalska, E., 1994. Direct and correlated response to the index with constrain in selection for body weight and feed conversion ratio in Japanese quail. Proc. $5^{\text {th }}$ WCGALP, Univ. Guelph, Ontario, Canada. 19, 103-106.

Mignon-Grasteau, S., David, J., Gibert, P., Legout, H., Petavy, G., Moreteau, B. \& Beaumont, C., 2004. REML estimates of genetic parameters of sexual dimorphism for wing and thorax length in Drosophila melanogaster. J. Genet. 83, 163-170.

Mohan, J., Moudgal, R.P., Venkata, K., Sastry, H., Tyagi, J. \& Singh, R., 2002. Effects of hemicastration and castration on foam production and its relationship with fertility in male Japanese quail. Theriogenology 58, 29-39.

Morrell, C.H., 1998. Likelihood ratio testing of variance components in the linear mixed effects model using restricted maximum likelihood. Biometrics 54, 1560-1568.

Oli, M.H., Hepp, G.R. \& Kennamer, R.A., 2002. Fitness consequences of delayed maturity in female wood ducks. Evol. Ecol. Res. 4, 523-576.

Oruwari, B.M. \& Brody, T., 1988. Roles of age, body weight, and composition in the initiation of sexual maturation of Japanese quail (Coturnix coturnix japonica). Br. Poult. Sci. 29, 481-488.

Potti, J. \& Merino, S., 1996. Parasites and the ontogeny of sexual size dimorphism in a passerine bird. Proc. R. Soc. Lond. B. 263, 9-12.

Reddish, J.M., Nestor, K.E. \& Lilburn, M.S., 2003. Effect of selection for growth on onset of sexual maturity in random bred and growth-selected lines of Japanese quail. Poult. Sci. 82, 187-191.

Ricklefs, R.E., 1985. Modification of growth and development of muscles in poultry. Poult. Sci. 64, 15631576.

Saatci, M., Ap Dewi, I. \& Aksoy, A.R., 2003. Application of REML. Procedure to estimate the genetic parameters of weekly live weights in one-to-one sire and dam pedigree recorded Japanese quail. J. Anim. Bred. Genet. 120, 23-28.

Schüler, L., Mielenz, N. \& Hempel, S., 1998. Asymmetry of the selection responses in performance traits of Japanese quail. Proc. $6^{\text {th }}$ WCGALP, Univ. New England, Armidale, Australia. 26, 101-104.

Sefion, A.E. \& Siegel, P.B., 1974. Inheritance of body weight in Japanese quail. Poult. Sci. 53, 1597-1603.

Seiwert, C.M. \& Adkins-Regan, E., 1998. The foam production system of the male Japanese quail: characterization of structure and function. Brain Behav. Evol. 52, 61-80.

Sezer, M. \& Tarhan, S., 2005. Model parameters of growth curves of three meat-type lines of Japanese quail. Czech. J. Anim. Sci. 50, 22-30.

Siegel, P.B. \& Dunnington, E.A., 1985. Reproductive complications associated with selection for broiler growth. In: Poultry Genetics and Breeding. Eds. Hill, W.G., Manson, J.M. \& Hewitt, D., Longman Group, Ltd, Harlow. pp. 59-72.

Stamps, J. \& Krishnana, V.V., 1997. Sexual bimaturation and sexual size dimorphism in animals with asymptotic growth after maturity. Evol. Ecol. 11, 21-39.

Stearns, S.C., 1992. The Evolution of Life Histories, Oxford University Press: New York.

Tosh, J.J. \& Kemp, R.A., 1994. Estimation of variance components for lamb weights in three sheep populations. J. Anim. Sci. 72, 1184-1190. 